\title{
Context-Dependent and Context-Independent Effects of D1 Receptor Antagonism in the Basolateral and Central Amygdala during Cocaine Self-Administration
}

\author{
(D)Earnest S. Kim and K. Matthew Lattal
}

https://doi.org/10.1523/ENEURO.0203-19.2019

Department of Behavioral Neuroscience, Oregon Health \& Science University, Portland, OR 97239-3098

\begin{abstract}
One way that drugs of abuse perturb the dopamine system is by triggering large amounts of extracellular dopamine to efflux into limbic regions. The basolateral (BLA) and central (CeA) nuclei of the amygdala have been shown to play distinct roles in value representation of primary and conditioned reward. However, the precise role of dopaminergic receptors in the BLA and the CeA during reward-related behaviors remains to be determined. Here we investigate the effects of dopamine D1 receptor blockade in the BLA and the CeA during asymptotic performance of cocaine self-administration and in a novel application of contextual renewal under continued access conditions. After more than three weeks of chained seek-take self-administration of cocaine, male Long Evans rats were given a bilateral intra-BLA or intra-CeA infusion of the D1 antagonist SCH-23390 $(2 \mu \mathrm{g} / 0.3 \mu \mathrm{l})$ for multiple days. Intra-BLA D1 receptor blockade before, but not after the self-administration session, gradually suppressed drug seeking and taking responses and persisted with a change in context with continued D1 blockade. In contrast, intra-CeA D1 receptor blockade caused a rapid reduction in self-administration that showed renewal with a change in context with continued D1 blockade. Further, conditioned place aversion developed with intra-BLA but not intra-CeA infusions. Collectively, these results demonstrate that dopamine D1 receptors in the BLA and $\mathrm{CeA}$ both contribute to drug seeking and taking, but may do so through distinct mechanisms.
\end{abstract}

Key words: amygdala; cocaine; contextual renewal; extinction; $\mathrm{SCH} 23390$; self-administration

\section{Significance Statement}

Drugs of abuse perturb the dopamine system by triggering large amounts of dopamine to efflux into limbic regions. The basolateral (BLA) and central (CeA) nuclei of the amygdala play distinct roles in value representation of primary and conditioned reward. However, the precise role of dopaminergic receptors in the BLA and the CeA during reward-related behaviors remains to be determined. Here we show that D1 antagonism in the BLA and CeA suppressed cocaine seeking and taking behavior, but only the BLA effect resisted contextual renewal. This study provides evidence for a novel method to weaken the effects of cocaine itself during active drug self-administration, and thereby provides insights into possible therapeutic interventions that may help prevent relapse. 


\section{Introduction}

Drug-seeking is thought to be maintained by a combination of positive and negative reinforcement processes that balance the appetitive and aversive effects of a drug. Although the amygdala is commonly associated with aversive processes, many studies have shown the importance of the amygdala in appetitive processes (Gallagher et al., 1990; Johnson et al., 2009). Appetitive and aversive outcomes, as well as cues that predict them, evoke dopamine efflux to the amygdala where D1- and D2-like receptors are expressed (Hurd et al., 1997; Guarraci et al., 1999, 2000; Weiss et al., 2000; Fotros et al., 2013; Abraham et al., 2014; Janak and Tye, 2015).

Much of what is known about the role of dopamine receptors in the amygdala in cocaine reward comes from models of relapse in which a self-administration phase is followed by instrumental extinction and a subsequent test for relapse under extinction conditions (See et al., 2003; Marchant et al., 2013). In this model, D1 receptor blockade has been shown to weaken cue but not drug-prime induced reinstatement of drug-seeking behavior (See et al., 2001). Although these studies have demonstrated dopaminergic function in the amygdala to be critical for conditioned stimuli to direct appropriate instrumental responses, most of these studies use extinction procedures where drug paired environments and responses are extinguished a number of days before an unextinguished drug paired conditioned stimulus is presented.

Recent approaches to drug-seeking and relapse incorporate conflict-based models in which aversive contingencies are added after a self-administration phase in which animals have continued drug access. In these models, inactivation of the basolateral (BLA) and the central nucleus of the amygdala (CeA) were found to increase context-induced relapse after punishment, but not after extinction. However, inactivation of the BLA, but not the $\mathrm{CeA}$, increased context-induced relapse in the acquisition context after punishment in an alternate context (Pelloux et al., 2018). These results highlight that the mechanisms that weaken maintained responding for drug reward are different depending on whether the behavioral approach involves removal of the drug reward or insertion of an aversive contingency during continued drug access conditions (Marchant et al., 2019). Given these findings, how dopaminergic function in the BLA and CeA can differentially modulate active drug self-administration where an animal has continued drug access remains unresolved.

This work was supported by National Institutes of Health Grants DA007262 (to E.S.K.), DA018165 (to K.M.L.), and DA025922 (to K.M.L.) and by the United States Department of the Army/DOD-TATRC Grant W81XWH-14-2-0143 (to K.M.L.).

Acknowledgements: We thank Tommy Navis for 3D printing catheter backpacks.

Correspondence should be addressed to K. Matthew Lattal at lattalm@ ohsu.edu.

https://doi.org/10.1523/ENEURO.0203-19.2019

Copyright (C) 2019 Kim and Lattal

This is an open-access article distributed under the terms of the Creative Commons Attribution 4.0 International license, which permits unrestricted use, distribution and reproduction in any medium provided that the original work is properly attributed.
In the following experiments, we evaluate the effects of delivery of the dopamine D1 receptor antagonist $\mathrm{SCH}$ 23390 to the BLA or CeA under continued drug access conditions. We find that antagonism of these receptors over multiple days results in rapid (in the case of $\mathrm{CeA}$ ) or gradual (in the case of BLA) weakening of cocaine selfadministration. The suppression of responding in the BLA is reversed when the antagonist is removed and the context is changed, but it persists across contexts when the antagonist continues to be delivered. In contrast, the rapid reduction in responding with $\mathrm{CeA}$ infusion is reversed with a context change even when the antagonist continues to be delivered in the new context.

\section{Materials and Methods}

\section{Subjects}

Male Long Evan rats (Charles River Laboratories) initially weighing $300-350 \mathrm{~g}$ (seven to eight weeks) were housed individually under a reverse 12/12 h light/dark cycle (light off at 7:00 A.M.; all experiments occurred during the dark phase). After surgery and a recovery period, rats were food restricted and maintained at $350-400 \mathrm{~g}$ during the course of the experiments. All experiments were performed according approved protocols by the Oregon Health \& Science University Institutional Animal Care and Use Committee. A total of 87 rats were used, with eight rats excluded for failure of catheter patency and five rats were excluded for misplaced cannulas.

\section{Intracranial and catheter surgery}

Rats were given an intraperitoneal injection of an induction anesthetic mixture of ketamine/xylazine $(94 \mathrm{mg} / \mathrm{kg}, 6.2 \mathrm{mg} /$ $\mathrm{kg}$ ) and maintained with isoflurane (1\%). Rats were implanted with chronic guide cannulas (22 gauge; Plastics One) in the CeA (AP: $-2.1 \mathrm{~mm}, \mathrm{ML}: \pm 4.0 \mathrm{~mm}, \mathrm{DV}:-6.2 \mathrm{~mm}$ ) or the BLA (AP: $-2.5 \mathrm{~mm}, \mathrm{ML}: \pm 5.2 \mathrm{~mm}, \mathrm{DV}:-7.4 \mathrm{~mm}$ ). Guide cannulae were positioned $\sim 0.75 \mathrm{~mm}$ above target sites using a Paxinos and Watson (1998) and permanently attached using six stainless-steel screws (MiniTaps) and dental cement. Dummy cannulas $(0.014-0.36 \mathrm{~mm}$, Plastics One) were inserted into guide cannulas until microinjection days. Rats were then implanted with an intravenous catheter constructed of SILASTIC laboratory tubing (Dow Corning) and inserted into the right jugular vein anchored with silk suture tied to a silicone gel ball (Silicon; DAP). The SILASTIC tubing ran subcutaneously and exited near the mid-scapular region and attached to a stainless-steel cannula (Plastics One Inc.) screwed into a custom-made backpack (Flashforge Creator Pro3D) designed in Tinkercad and printed using Simplify 3D. Following implantation, the catheter was injected daily with sulfamethoxazole trimethoprim (TEVA) and heparin to maintain catheter patency and reduce infection. Rats were given 5-7 d to recover and were given ad libitum food and water before self-administration behavior. Catheter patency was confirmed with sodium brevital (2 $\mathrm{mg} / \mathrm{kg}$ ) as needed.

\section{Self-administration (Experiments 1-3) Apparatus}

Contexts A and B: two separate contexts (A and B) were used where the floor, the visual cues, and the spatial location of half of the chambers in each room were al- 
tered. Context A consisted of a grid floor of 19 large (4.8 $\mathrm{mm}$ ) diameter bars spaced $15.6 \mathrm{~mm}$ apart, a clear Plexiglas back wall, and was located in a different location (vertically and horizontally) within each testing room. Context B consisted of a grid floor of 26 smaller (3.2-mm) diameter bars spaced $8.0 \mathrm{~mm}$ apart, a black and white striped back wall, and in a distinct location (vertically and horizontally) within each testing room. Both sets of chambers had a house light and two retractable levers with a cue light above each lever.

\section{General behavioral methods}

Behavioral experiments were performed in the operant chambers described above (Med Associates). One lever was paired with a cocaine infusion (take lever) while the other lever was designated as a seek lever (counterbalanced). All experiments began with levers retracted and the house light extinguished. Rats were food restricted to maintain starting body weight and dosage during the course of the experiment.

\section{Self-administration training of a cocaine seek-take chain} schedule of reinforcement

The seek-take procedure was modified from procedures described previously (Chen et al., 2013; Alaghband et al., 2018). Briefly, self-administration training began after $1 \mathrm{~min}$ with an insertion of a take lever and the illumination of the house light. One lever press on the take lever resulted in a single 5-s cocaine infusion $(0.45-0.48$ $\mathrm{mg} \mathrm{kg}^{-1}$ at a rate of $0.088 \mathrm{ml} / 5 \mathrm{~s}$ ), retraction of the take lever, illumination of a cue light above the take lever for 5 $\mathrm{s}$, and extinction of the house light. Following a 30-s inter-trial interval, another trial was initiated with an insertion of the take lever and illumination of the house light. After stable responding of 30 infusions across two consecutive days, a seek lever was inserted with the take lever retracted and the house light illuminated. One press on the seek lever resulted in the retraction of the seek lever and insertion of the take lever. One press on the take lever resulted in a single cocaine infusion and illumination of the cue light above the take lever. After stable responding of 30 infusions across two consecutive days, a variable interval schedule on the seek lever of VI2, VI3, VI5, and $\mathrm{Vl} 10$ seconds was introduced each consecutive day. Training sessions terminated after either 30 infusions or 4 h. Rats were maintained on the VI 10-FR1 schedule of reinforcement throughout the rest of each experiment, except where noted below.

\section{Experiment 1A: Effects of BLA SCH 23390 on mainte- nance and renewal}

Rats were trained in Context $A$ on the seek-take task. After $3 \mathrm{~d}$ of stable baseline responding, $\mathrm{SCH} 23390(n=$ $13)$ or saline $(n=10)$ was given before self-administration sessions in the BLA for $3 \mathrm{~d}$ (Phase 1). Subsequently, rats given $\mathrm{SCH} 23390$ were given saline and rats given saline were given $\mathrm{SCH} 23390$ (Phase 2). On discovering an order effect in the first cohort, only rats in the Sal/SCH group received continued seek-take training $2 \mathrm{~d}$ (Days 10 and 11) and then were moved to Context $B$ for two additional days (Days 12 and 13). Subsequently, rats were moved back to Context A (Day 14). Four animals lost patency during the course of the experiment and was excluded. Throughout the context changes, rats had continued drug access and did not have any intra-BLA injections.

Experiment 1B: Effects of post-session BLA SCH 23390 on maintenance

A separate naïve group of rats $(n=6)$ were cannulated, catheterized, and trained on the seek-take task as described above. After stable baseline was reached, rats were injected with SCH 23390 after cocaine selfadministration sessions for $3 \mathrm{~d}$, followed by a return to baseline with no intra-BLA injection for $2 \mathrm{~d}$.

\section{Experiment 2: Effects of BLA or CeA SCH 23390 on maintenance}

Two groups of rats were catheterized and cannulated in the BLA $(n=7)$ or the CeA $(n=7)$ and trained on the seek-take task for an equivalent number of days. The BLA and $\mathrm{CeA}$ cannulated groups did not differ in the level of drug exposure during acquisition or in the rate of acquisition of the seek-take procedure. After $3 \mathrm{~d}$ of baseline, both groups were given SCH 23390 before the self-administration sessions for $3 \mathrm{~d}$ then given saline for three additional days.

\section{Experiment 3: Effects of BLA or CeA SCH 23390 on} maintenance and renewal

Two groups of rats were catheterized, cannulated in the BLA $(n=10)$ or the CeA $(n=14)$, and trained on the seek-take task for an equivalent number of days in Context A (context identity was counterbalanced between Contexts $\mathrm{A}$ and B). After $3 \mathrm{~d}$ of baseline, rats were given $\mathrm{SCH} 23390$ $(n=17)$ or saline (BLA/CeA: $n=7)$ for $4 \mathrm{~d}$. On the 3rd day of $\mathrm{SCH} 23390$ or saline, all groups were moved to Context $\mathrm{B}$ (counterbalanced). On the 4th day of SCH 23390 or saline, all groups were moved back to Context A. Both groups had drug access throughout the experiment.

\section{Microinjection procedures}

During injection days, dummy cannulas were removed and injection cannulas attached to $1-\mu \mathrm{l}$ Hamilton syringes were inserted bilaterally into guide cannulas. A total volume of $0.3 \mu$ l of either saline $(0.9 \%)$ or D1 antagonist $(\mathrm{SCH}$ 23390) was injected at a rate of $0.1 \mu \mathrm{L} / \mathrm{min}$ using a microinjection pump (Chemyx) $\sim 4$ min before a selfadministration session. The microinjecter was left in place for $1 \mathrm{~min}$ to allow for diffusion.

\section{Drugs}

$\mathrm{SCH} 23390$ (Tocris) was dissolved in saline $(0.9 \% \mathrm{NaCl})$ to a concentration of $2 \mu \mathrm{g} / 0.3 \mu \mathrm{l}$. Cocaine hydrochloride was dissolved in saline to a concentration of $2 \mathrm{mg} / \mathrm{ml}$.

\section{Conditioned place aversion (Experiment 4)}

Apparatus and general behavioral methods

Place conditioning followed the unbiased apparatus and procedures outlined by Cunningham et al. (2006) and used previously by our lab to assess BLA function (Bernardi et al., 2009). The apparatus consisted of identical boxes $(48 \times 16 \times 20 \mathrm{~cm})$ in sound attenuating chambers that were custom fabricated (McCarthy Manufacturing) with a camera mounted $46 \mathrm{~cm}$ above each box and an IR light source mounted $43 \mathrm{~cm}$ along the long wall of each box. Video was collected and analyzed using ANY-maze 
behavioral tracking software (Stoelting). The floor of each box consisted of interchangeable halves made of a grid floor or a hole floor that were $26.5 \times 20.5 \mathrm{~cm}$ raised on a $2.5-\mathrm{cm}$ acrylic frame. The grid floor consisted of 2.3- $\mathrm{mm}$ stainless-steel rods mounted $13 \mathrm{~mm}$ apart. The hole floor consisted of a perforated stainless-steel plate with $13-\mathrm{mm}$ round holes. There were three phases in the experiment over $5 \mathrm{~d}$ : pretest (one session: $30 \mathrm{~min}$ ), conditioning (three sessions: $60 \mathrm{~min}$ ), and testing (one session: $30 \mathrm{~min}$ ). Rats were given intracranial surgery as described above using the CeA and BLA coordinates $7 \mathrm{~d}$ before the first phase and were randomly assigned to one of four groups: hole + $(n=5)$, hole $-(n=5)$, grid $+(n=5)$, and grid $-(n=5)$. Rats were tracked using the center point of the animal.

Pretest

Rats were placed into the apparatus consisting of a half grid floor and a half hole floor, with the position of the floors counterbalanced within each subgroup to test for a natural preference. After $30 \mathrm{~min}$, rats were returned to their home cages.

\section{Conditioning}

Twenty-four hours after pretest, rats were microinjected with saline (0.9\%; CS -) or with D1 antagonist $(2.0 \mu \mathrm{g} / .3 \mathrm{uL}$; $\mathrm{CS}+$ ) into the BLA or CeA as described above. Injectors were left in place for $1 \mathrm{~min}$ following injection to allow for diffusion. Immediately after, rats were placed into the apparatus with one floor type either hole or grid. The order of the CS + and CS- was counterbalanced each day within each subgroup. Conditioning sessions were $60 \mathrm{~min}$ each day for $3 \mathrm{~d}$.

\section{Testing}

Twenty-four hours after the last conditioning session, rats were placed into the apparatus consisting of a half hole floor and a half grid floor, with the position of the floor counterbalanced within each subgroup. Preference was determined by time spent on the CS + side and CS-, with a middle zone of $18 \mathrm{~cm}$ (the approximate length of a rat) excluded to account for when rats were both on the hole and grid floors. After $30 \mathrm{~min}$, rats were returned to their home cages. Rats were not injected on test day.

\section{Statistical analyses}

Seek and take lever instrumental responding in selfadministration sessions were analyzed using a two-way ANOVA with session, time within session, or a context as a repeated factor, drug treatment as the between-subjects factor, and seek and take presses, or time to complete each session as the dependent variable. Bonferroniadjusted, two-tailed, paired-samples $t$ tests or independent $t$ tests were used for post hoc tests where appropriate. All data were represented as the mean \pm SEM. Statistical tests where $p \leq 0.05$ was considered significant and statistics are reported in the statistical table (Table 1).

\section{Time bin analysis}

Drug seek responses were binned and averaged every minute and a group raster plot was analyzed and constructed with EITemps software (A. Diez Noguera, University of Barcelona, Spain).

\section{Results}

\section{Dopamine D1 receptor antagonism in the BLA progressively reduces intravenous cocaine self- administration}

Two groups of rats were trained on a V10-FR1 seek-take chain schedule of reinforcement to procure intravenous cocaine rewards in Experiment $1 \mathrm{~A}$ (Fig. 1A). After stable baseline of seek and take responses, rats were given the D1 antagonist SCH $23390(2 \mu \mathrm{g} / 0.3 \mu \mathrm{L})$ or saline injections into the BLA before self-administration sessions for three consecutive days (Phase 1). Subsequently, conditions were reversed such that the $\mathrm{SCH} 23390$-treated group was given saline and the saline-treated group was given $\mathrm{SCH} 23390$ for three additional days (Phase 2 ). In both conditions, BLA D1 receptor blockade progressively decreased cocaine seeking (Fig. 1B) and taking (Fig. 1D) behavior compared to the saline-treated group (ANOVA: Phase 1 seek: day $\times$ group: $F_{(2,36)}=3.150, p=0.05$, take: day $\times$ group: $F_{(2,36)}=5.21, p$ $=0.01$; Phase 2 seek: day $\times$ group: $F_{(2,24)}=9.46, p=0.001$; take: day $\times$ group: $\left.F_{(2,24)}=15.34, p=0.00005\right)$. Post hoc analysis revealed a significant group difference on seek and take lever presses on Day $2(p<0.008)$ and Day $3(p<$ 0.001 ) of drug treatment and was accompanied with an increase of time to complete each session (ANOVA: Phase 1: $F_{(1,22)}=10.467, p=0.007$, Day 2: $F_{(1,20)}=17.79, p=$ 0.0004, Day 3: $F_{(1,19)}=35.285, p=0.00001$, Phase 2: Day 1: $F_{(1,18)}=0.004, p=0.953$, Day $2: F_{(1,16)}=13.586, p=$ $0.002, F_{(1,15)}=8.174, p=0.013$; repeated measures ANOVA: Phase 1: day $\times$ group: $F_{(2,36)}=0.415, p=0.664$; Phase 2: day $\times$ group: $F_{(2,28)}=4.708, p=0.017$; Fig. $\left.1 C\right)$. Post-session delivery of SCH 23390 did not alter drug seeking or taking responses or time to complete the session in Experiment 1B, suggesting that the D1 blockade weakened responding for cocaine without affecting memory consolidation (seek: $F_{(6,18)}=0.154, p=0.986$; time: $F_{(6,18)}=1.59$, $p=0.206$; Fig. 1E)

A time bin analysis of seek presses revealed a distinct pattern of responding during drug treatment. Figure $2 \mathrm{~A}$ shows within-session responding during baseline and three $\mathrm{SCH} 23390$ sessions. Figure $2 \mathrm{C}-E$ shows raster plots of the subgroups that received SCH 23390 before saline (SCH/Sal; Fig. 2C), saline before SCH 23390 (Sal/ $\mathrm{SCH}$; Fig. 2D), and saline before SCH 23390 followed by context change (Fig. 2E). While during baseline sessions, rats exhibited continuous pressing activity that lasted on average $2.06 \mathrm{~h}$ (SD 0.67), BLA D1 blockade resulted in a $U$-shaped pattern of responding typically lasting the entire session with responding highest at the beginning and end of each session (Fig. 2A,C-E). On Days 2 and 3 of drug treatment, both groups showed a greater suppression of responses, and continued to show a U-shaped pattern of responding. Counterbalancing drug treatment revealed that rats given SCH 23390 first (SCH/SAL; Fig. 2B,C) continued to show a persistent decrease in the rate of cocaine infusions after they were switched to saline, compared to rats given $\mathrm{SCH} 23390$ after saline [SAL/SCH (Fig. $2 B, D) ;$ SAL/SCH vs SCH/SAL: $\left.t_{(11)}=2.68, p=0.02\right]$.

To assess the persistence of the $\mathrm{SCH} 23390$-induced reduction in cocaine self-administration, rats given saline 
Table 1. Summary of statistical analysis

\begin{tabular}{|c|c|c|c|c|}
\hline & Test & $n$ & Comparison & $\begin{array}{c}\text { Statistical } \\
\text { significance }\end{array}$ \\
\hline \multirow[t]{2}{*}{$1 B$} & Repeated measures & $\mathrm{D} 1=13$, saline $=10$ & (Seek) day $\times$ group phase 1 & $p=0.05$ \\
\hline & ANOVA + Bonferroni & & (Seek) day $\times$ group phase 2 & $p=0.001$ \\
\hline \multirow[t]{2}{*}{$1 D$} & & & (Take) day $\times$ group phase 1 & $p=0.01$ \\
\hline & & & (Take) day $\times$ group phase 2 & $p=0.00005$ \\
\hline \multirow[t]{2}{*}{$1 B, D$} & & & (Seek + take) post hoc day 2 D1 vs saline & $p<0.008$ \\
\hline & & & (Seek + take) post hoc day 3 D1 vs saline & $p<0.001$ \\
\hline \multirow[t]{6}{*}{$1 C$} & ANOVA & $\mathrm{D} 1=13$, saline $=10$ & Saline vs D1 day 1 phase 1 & $p=0.007$ \\
\hline & & & Saline vs D1 day 2 phase 1 & $p=0.0004$ \\
\hline & & & Saline vs D1 day 3 phase 1 & $p=0.00001$ \\
\hline & & & Saline vs D1 day 1 phase 2 & $p=0.953$ \\
\hline & & & Saline vs D1 day 2 phase 2 & $p=0.002$ \\
\hline & & & Saline vs D1 day 3 phase 2 & $p=0.013$ \\
\hline \multirow[t]{2}{*}{$1 C$} & Repeated measures & $\mathrm{D} 1=13$, saline $=10$ & Day $\times$ group phase 1 & $p=0.664$ \\
\hline & ANOVA + Bonferroni & & Day $\times$ group phase 2 & $p=0.017$ \\
\hline \multirow[t]{2}{*}{$1 E$} & ANOVA & $\mathrm{D} 1=6$, saline $=6$ & Seek & $p=0.986$ \\
\hline & & & Time & $p=0.206$ \\
\hline $2 B$ & $t$ test & $\mathrm{D} 1=13$, saline $=10$ & Day 3 SAL/SCH vs SCH/SAL & $p=0.02$ \\
\hline \multirow[t]{2}{*}{$2 B$} & Paired $t$ test & $n=6$ & Day 11 vs day 12 & $p=0.00037$ \\
\hline & & & Day 13 vs day 14 & $p=0.01651$ \\
\hline \multirow[t]{3}{*}{$3 A$} & Repeated measures & $\mathrm{CeA}=6, \mathrm{BLA}=7$ & Session $\times$ group & $p=0.049$ \\
\hline & ANOVA + Bonferroni & & BLA vs CeA day 1 & $p=0.038$ \\
\hline & & & BLA vs CeA day $2+3$ & $p>0.363$ \\
\hline \multirow[t]{2}{*}{$3 B$} & Repeated measures & $\mathrm{CeA}=8, \mathrm{BLA}=9$ & Group $\times$ room & $p=0.003$ \\
\hline & ANOVA + Bonferroni & & Context B: CeA vs BLA & $p=0.0001$ \\
\hline $3 B$ & One-way ANOVA & Sal $=7$ & baseline, context shift, original context & $p=0.6$ \\
\hline \multirow[t]{6}{*}{$4 A$} & Repeated measures & Sal $=10, B L A=11, \mathrm{CeA}=5$ & Main effect test & $p<0.0001$ \\
\hline & ANOVA + Bonferroni & & Main effect group & $p<0.00006$ \\
\hline & & & Day $\times$ group & $p=0.05$ \\
\hline & & & BLA vs saline $45 \mathrm{~min}$ & $p<0.01$ \\
\hline & & & CeA vs saline 15 and $30 \mathrm{~min}$ & $p \leq 0.05$ \\
\hline & & & Saline vs BLA and CeA 60 min & $p>0.1$ \\
\hline \multirow[t]{3}{*}{$4 B$} & One-way ANOVA & Sal $=10, B L A=11, \mathrm{CeA}=5$ & BLA vs saline & $p=0.000007$ \\
\hline & & & BLA vs CeA & $p=0.001$ \\
\hline & & & CeA vs saline & $p=0.669$ \\
\hline \multirow[t]{3}{*}{$4 D$} & ANOVA & Sal $=10, B L A=11, \mathrm{CeA}=5$ & Main effect test & $p=0.001$ \\
\hline & & & Main effect group & $p=0.971$ \\
\hline & & & Group $\times$ test & $p=0.792$ \\
\hline
\end{tabular}

then SCH 23390 were maintained on the seek-take procedure with no intra-BLA injections for $2 \mathrm{~d}$ in the drug acquisition context (CTX A: Days 10-11), moved to a distinct context for two additional days (CTX B: Days 12-13), and then placed back into the original context (CTX A: Day 14; Fig. 2B, right panel), all with continued access to cocaine. Subsequent rate analysis revealed that rats increased the number of infusions/hour when moved to Context B (paired $t$ test: $t_{(5)}=8.5, p<0.01$ ), then decreased the rate of responding when returned to Context $A$ (paired $t$ test: $t_{(5)}=3.97, p<0.01$; Fig. $2 B, E$ ), suggesting that $\mathrm{SCH} 23390$ delivery resulted in a persistent, context-specific attenuation of self-administration.

\section{The time course of the suppressive effects of D1 receptor antagonism in the BLA and CeA differs during maintained self-administration}

There is much evidence that the CeA and BLA play distinct roles in reward learning (Parkinson et al., 2000). To investigate the suppressive effects of D1 blockade in the $\mathrm{CeA}$ and BLA, two groups of rats were catheterized and cannulated in the $\operatorname{CeA}(n=6)$ or the $\operatorname{BLA}(n=7)$ and trained on the seek-take task as described above. Consistent with Experiment 1, D1 BLA blockade in Experiment 2 progressively decreased cocaine self-administration through $3 \mathrm{~d}$ of treatment (Fig. 3A). However, D1 CeA blockade reduced cocaine self-administration rapidly in the first session and persisted through additional sessions of SCH treatment (session $\times$ group: $F_{(2,20)}=3.52, p=$ 0.049). Post hoc analysis revealed a significant group difference on Day $1(p=0.038)$. Both the BLA and CeA groups recovered their drug-seeking responses when subsequently treated with saline, mirroring the residual D1 blockade effects by $\mathrm{SCH} 23390$ we observed in the first experiment.

\section{D1 receptor antagonism in the CeA or BLA suppresses cocaine self-administration, but the CeA-induced suppression reverses with a context change}

In Experiment 3, rats were catheterized and cannulated in the $\mathrm{CeA}(n=8)$ or BLA $(n=9)$ and were trained on the seek-take task and given $\mathrm{SCH} 23390$ or saline for $4 \mathrm{~d}$ after $3 \mathrm{~d}$ of baseline in a ABA context renewal procedure (Fig. 


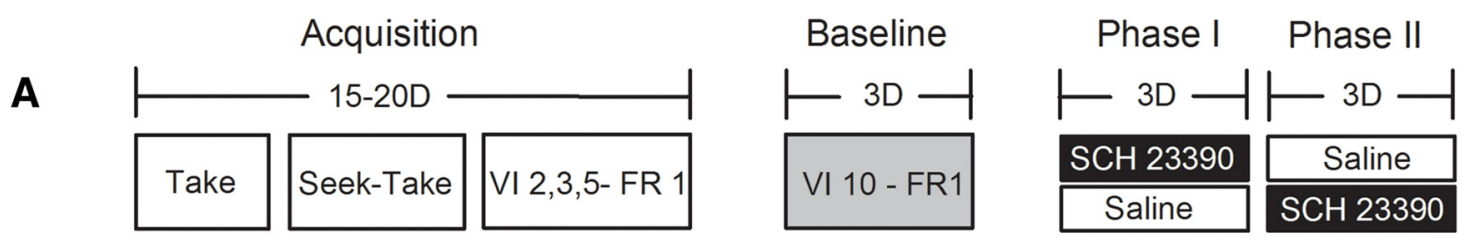

B
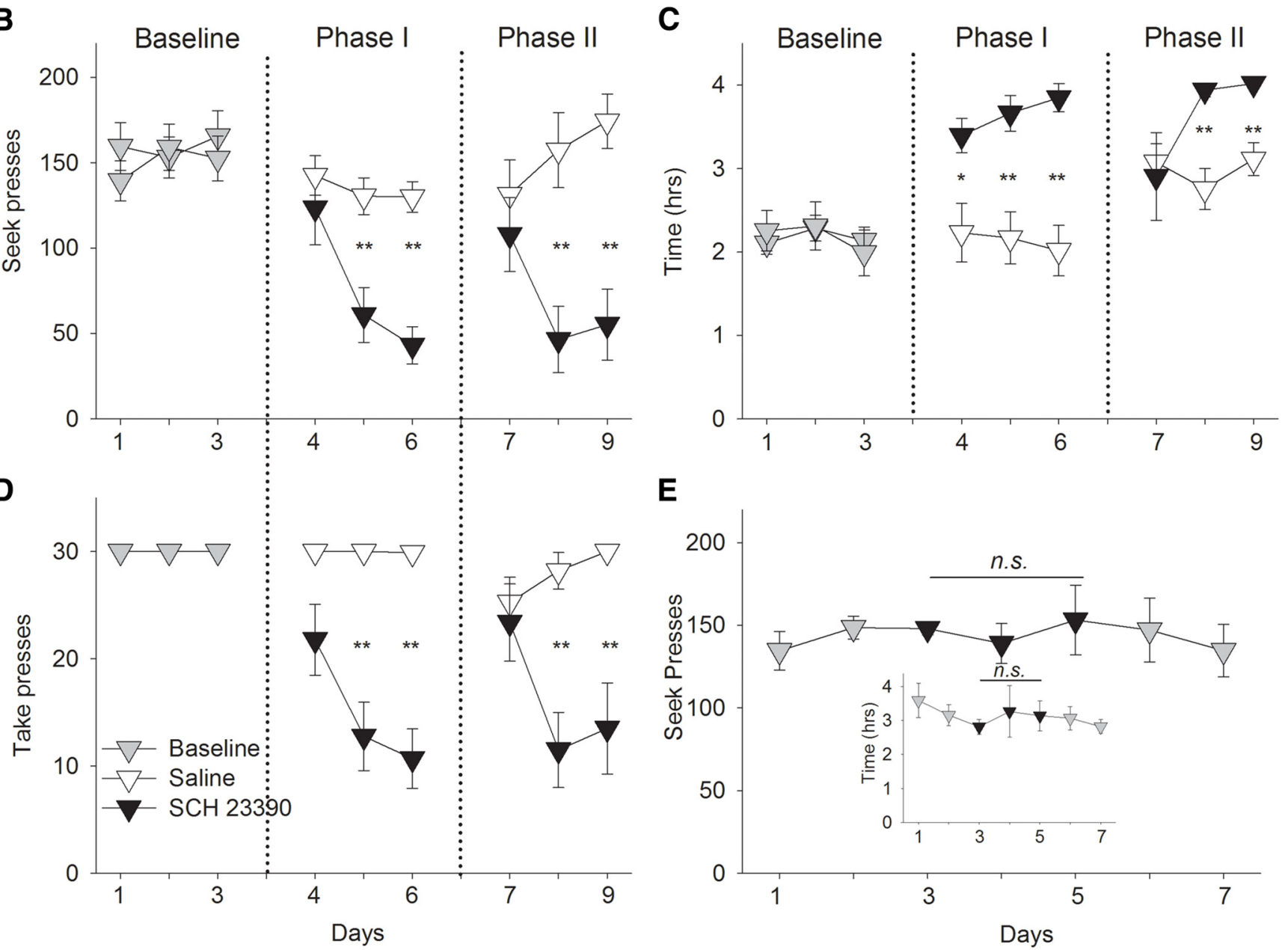

$\mathbf{E}$

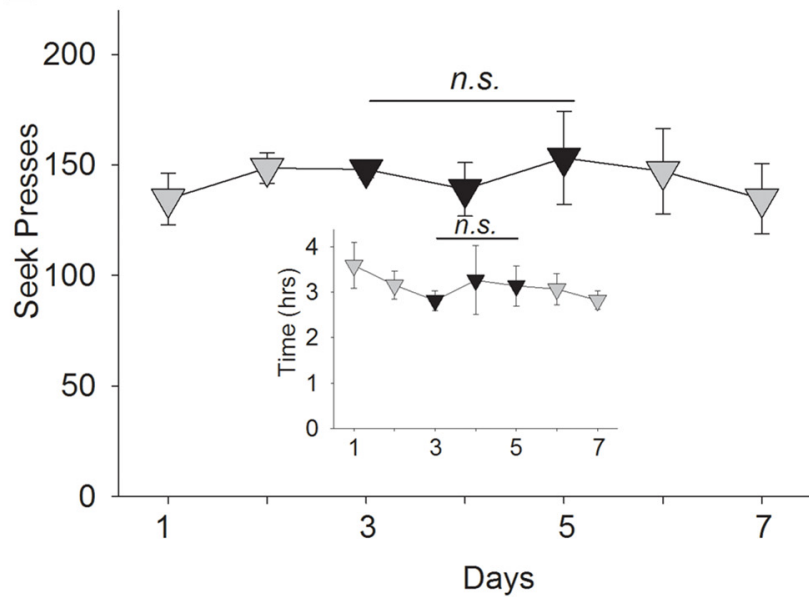

Figure 1. Intra-BLA D1 blockade by SCH 23390 progressively decreases cocaine seeking and taking behavior and increases the time to complete each session in Experiment 1. A, Experimental timeline showing the seek-take procedure from acquisition, baseline, Phase 1, and Phase 2 in Experiment 1A. After the acquisition period of 15-20 d, $3 \mathrm{~d}$ of stable baseline were recorded before SCH $23390(n=13,2.0 \mu \mathrm{g} / 0.3 \mu \mathrm{l})$ or saline $(n=10,0.3 \mu \mathrm{l})$ was injected before each session (Phase 1). Subsequently, SCH $23390-$ treated rats were given saline and saline-treated rats were given SCH 23390 for three additional days (Phase 2). B, SCH 23390 (black filled) administered before each session progressively decreased cocaine seeking. Post hoc analysis revealed differences between saline on Days 2 and 3 of drug treatment $(p<0.05)$. $\mathbf{C}$, SCH 23390 treatment resulted in an increase in the time to complete each session compared to saline controls (white unfilled). Post hoc analysis revealed differences between saline and drug treatment $(p<0.05)$. $\boldsymbol{D}$, SCH 23390 decreased cocaine taking behavior on Days 2 and 3 of drug treatment $(p<0.05)$. E, In Experiment 1B, SCH 23390 administered after each session (black filled; $n=6$ ) did not alter subsequent cocaine seeking and taking behavior or time to complete each session, relative to two sessions of baseline (gray filled) before and after SCH 23390 treatment (inset; $p>0.1$ ). Error bars indicate SEM; $* * p<0.01, * p<0.05$. n.s., non significant.

3B). Similar to Experiment 2, both groups decreased drug seeking during $2 \mathrm{~d}$ of SCH 23390 delivery in Context A with the CeA group showing greater sensitivity to D1 blockade on Day 1. However, when moved to a novel Context B, the CeA group, but not BLA group, increased cocaine self-administration during concurrent D1 blockade (ANOVA: group $\times$ room $F_{(2,39)}=6.92, p=0.003$, context B: CeA vs BLA, $p=0.0001$; for group raster plot, see Fig. $3 C$ ). During the 4th day of D1 blockade, the BLA and $\mathrm{CeA}$ group were returned to Context $\mathrm{A}$ where both groups again showed a suppression of cocaine selfadministration. The saline group $(n=7)$ did not differ in responding through baseline, saline treatment during the context shift, and saline treatment back in the original context (one-way ANOVA: $F_{(3,45)}=0.54, p=0.6$ ). These results suggest $D 1$ activity in the $B L A$, but not the $C e A$, to 
A

B

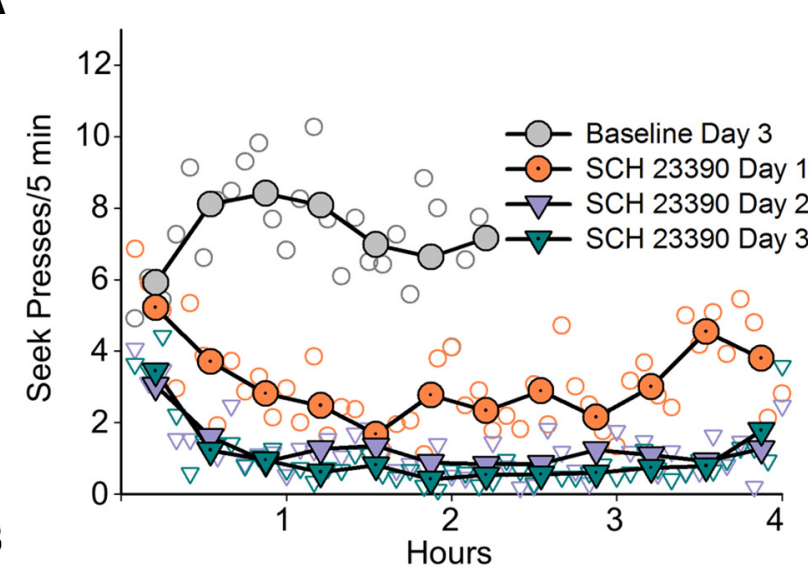

C

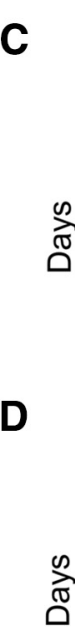

Hours

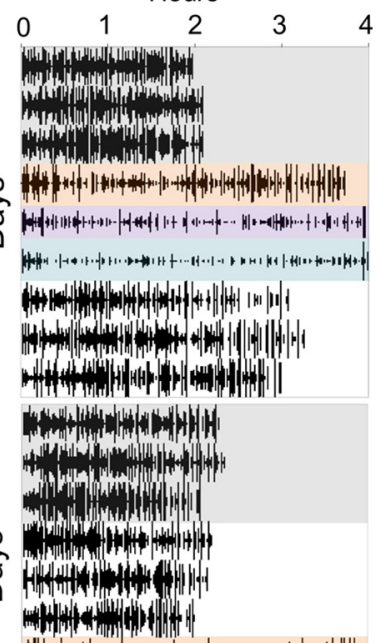


A
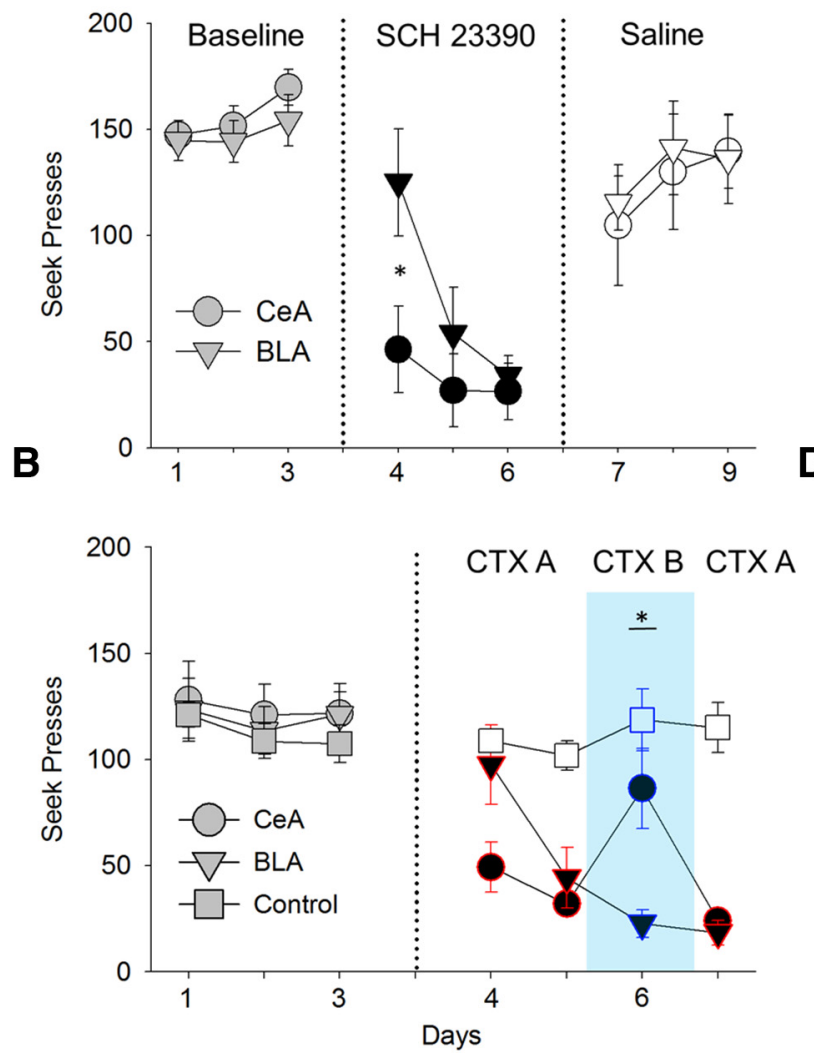

C
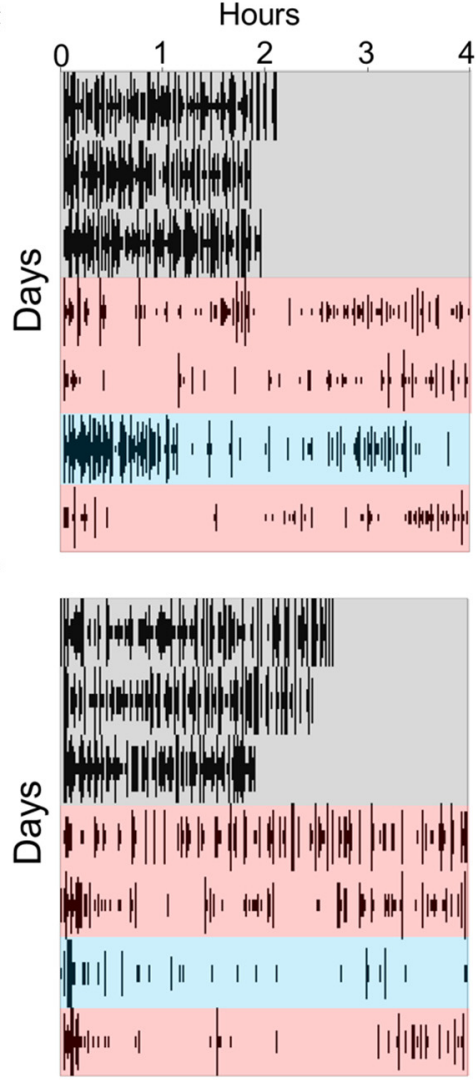

Figure 3. Different sensitivities of suppression between the CeA and BLA on cocaine-seeking behavior and effects on contextual renewal during concurrent D1 blockade in Experiments 2 and 3. $\boldsymbol{A}$, While D1 blockade (dark filled) in the CeA ( $n=6)$ rapidly decreased cocaine-seeking behavior, D1 blockade in the BLA $(n=7)$ progressively decreased cocaine-seeking behavior. Saline treatment recovered cocaine-seeking behavior in both the CeA and BLA group. $\boldsymbol{B}$, Consistent with the results found in Figure $2 A$, D1 blockade in the $\mathrm{BLA}(n=8)$ and the $\mathrm{CeA}(n=9)$ differentially decreased cocaine-seeking behavior over $2 \mathrm{~d}$ in the training context (Context $\mathrm{A}$; red outline) while saline controls (white unfilled: BLA/CeA, $n=7$ ) did not change. On the 3rd day of D1 blockade or saline, groups were moved to Context B (cyan), where the CeA group, but not the BLA group, increased cocaine-seeking behavior $(p<0.05)$. On the 4th day of D1 blockade, groups were returned to Context A, where both groups showed a suppression of cocaine-seeking behavior. Group raster plot of seek lever presses of the CeA group (C) and BLA group (D) during baseline (charcoal), SCH 23390 treatment in context A (red), SCH 23390 treatment in context B (cyan), and SCH 23390 treatment back in Context $\mathrm{A}$ (red); $* * p<0.01$, $* p<0.05$.

(group: $F_{(2,38)}=0.029, p=0.971$, group $\times$ test: $F_{(2,38)}=$ $0.238, p=0.792$; Fig. $4 D$ ).

\section{Discussion}

These experiments found that dopamine D1 receptor antagonism by SCH 23390 in the BLA or CeA disrupted stable cocaine self-administration. The speed with which these effects occurred, as well as their persistence with a change in context, differed between the two regions. BLA blockade of D1 receptors induced a gradual U-shaped pattern of suppression within and between cocaine selfadministration sessions (Experiments 1 and 2). This effect persisted when SCH 23390 was removed with continued cocaine access, but reversed with continued access in a new context (Experiment 1). When SCH 23390 continued to be delivered, the suppression persisted into a new context (Experiment 3). In contrast, D1 antagonism in the CeA caused a rapid decrease in cocaine self-administration (Experiments 2 and 3 ) that reversed with a shift to a new context, even in the continued presence of $\mathrm{SCH}$ 23390. Together, these results suggest that D1 receptors in the BLA and $\mathrm{CeA}$ contribute to maintained cocaine self-administration, but may do this through mechanisms that are differentially mediated by contextual associations.

Within and between sessions in the same context, D1 antagonism in the BLA or CeA resulted in attenuated self-administration under continued access procedures. In the $\mathrm{CeA}$, this attenuation was rapid. In the BLA, the attenuation was more gradual, with a progressive U-shaped suppression of drug seeking responses to intra-BLA D1 blockade within a session, suggesting that $\mathrm{SCH} 23390$ competed with reinforcing properties of cocaine selfadministration. Previous research has shown that striatal levels spike at $30 \mathrm{~min}$ and last up to $4 \mathrm{~h}$ with a subcutaneous injection of SCH 23390 (Hietala et al., 1992). Although the half-life of $\mathrm{SCH} 23390$ in the amygdala is not 
A

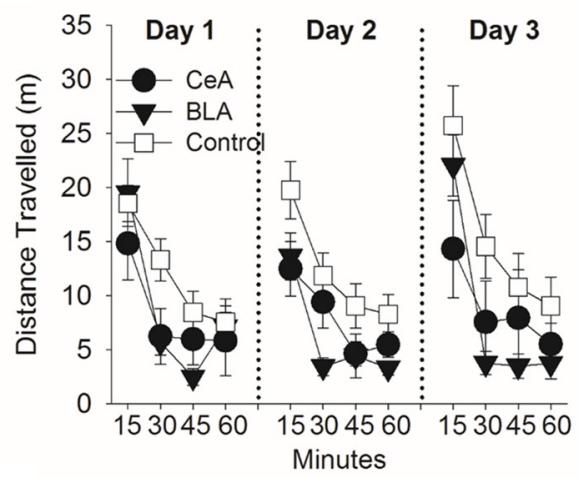

C
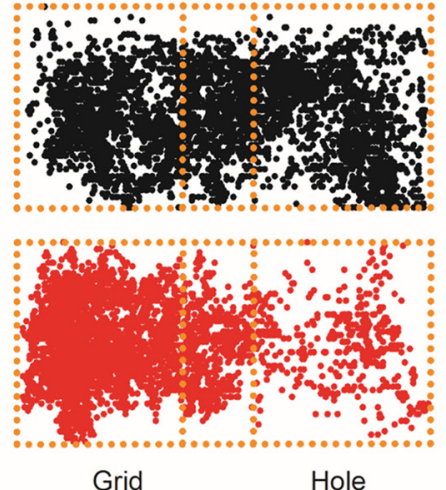

B

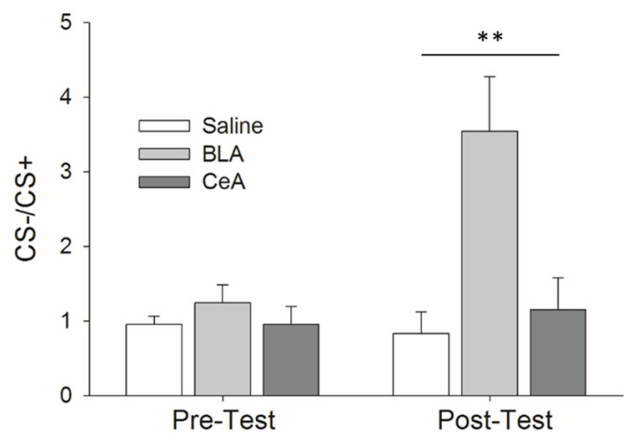

D

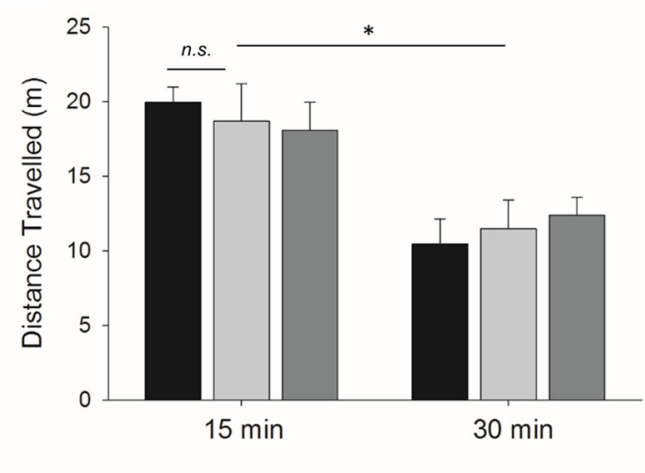

Figure 4. Intra-BLA, but not intra-CeA, D1 blockade by SCH 23390 for 3 d results in a conditioned place aversion in Experiment 4. $\boldsymbol{A}$, Saline $(n=10)$, BLA $(n=11)$, and CeA $(n=5)$ groups decreased their distance traveled within each session of conditioning, but the BLA and CeA group given $\mathrm{SCH} 23390$ (black filled) had a larger decrease then saline controls (unfilled; $p \leq 0.05$ ). $\boldsymbol{B}$, Saline, BLA, and $\mathrm{CeA}$ groups did not have a preference for the grid or hole floors during the pre-test. However, after $3 \mathrm{~d}$ of conditioning, the BLA, but not the saline or CeA groups, showed a significant conditioned place aversion (CS-/CS+: ratio of time spent in non-conditioned side vs conditioned side) during the post hoc test $(p<0.05)$. $C$, Representative tracking plots of rats during post hoc test for saline (top, black) and intra-BLA SCH 23390 (red, bottom) groups injected during training on the hole floor. A mid-zone compartment of 18 $\mathrm{cm}$ in length (the approximate length of the body of an animal) was used in the analysis to account for when the animal was both on the grid and hole floors. $\boldsymbol{D}$, While all three groups decreased their distance traveled during the post hoc test, there were no differences between groups $(p>0.9)$; $* * p<0.01, * p<0.05$. n.s., non significant.

known, the drug-seeking data suggest suppression to begin $30 \mathrm{~min}$ into the session, while recovery of responses begins near the end of the 4-h session. However, with repeated sessions with BLA D1 blockade, the U-shaped suppression of drug seeking became more pronounced, consistent with learned suppression of responding over the course of repeated sessions with the antagonist. The gradual effect that emerged over days is consistent with other studies of the BLA, which have found a delayed effect of BLA lesions on cue-induced reinstatement with no immediate effect on maintained cocaine self-administration (Meil and See, 1997). These and other findings suggest the importance of multiple long-term behavioral tests to reveal amygdala function in drug reward (Baxter and Murray, 2002; Pizzimenti et al., 2017).

\section{Context changes reveal differences in persistence of D1 antagonism effects}

The suppressive effect was reversed when SCH 23390 was removed during continued access conditions in the same context or when the context was changed under conditions without $\mathrm{SCH}$ 23390. When continued access continued in the presence of SCH 23390 in a different context, the suppressive effect persisted in the BLA, but reversed in the $\mathrm{CeA}$. This finding of weakened renewal during continued access in the BLA is consistent with other studies that have found that D1 blockade before a nonreinforced test of cue- or context-induced reinstatement weakens responding (Alleweireldt et al., 2002; Crombag and Shaham, 2002; Hamlin et al., 2006, 2007). The differences in the speed with which BLA and CeA effects occurred and their persistence across contexts is unlikely due to effects on motor function because $\mathrm{SCH}$ 23390 in either region resulted in similar decreases in locomotion in Experiment 4, but differences in the speed with which instrumental responding decreased in Experiments 1-3. One caveat between the experiments is that the effect of D1 antagonism on locomotion in the CPA experiment was in naive rats, whereas the rats in the self-administration experiments had a history of cocaine. Perhaps the magnitude of the locomotor effects of D1 


\section{CeA}

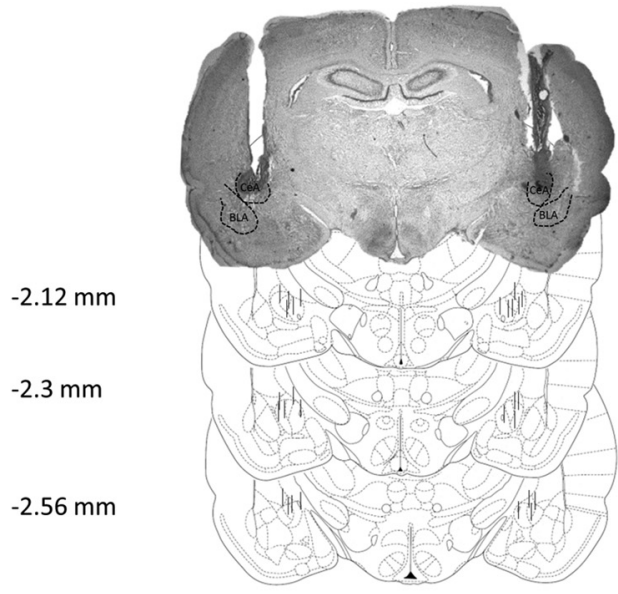

BLA

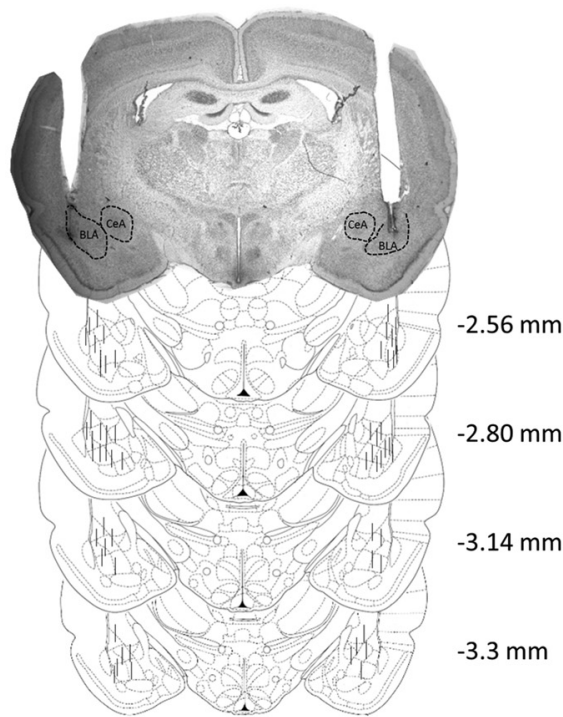

Figure 5. Reconstruction of cannula placement for CeA and BLA groups with representative CeA and BLA photomicrographs. Each charcoal line represents the tip of the infusion cannula that protruded $(\sim 0.75 \mathrm{~mm})$ from the guide cannula.

antagonism in the BLA may vary with a history of cocaine self-administration. However, post-session administration of $\mathrm{SCH} 23390$ was without effect, consistent with an interaction between the antagonist and the experience during the self-administration session, again suggesting that blockade in the amygdala alters learning processes to weaken instrumental responding.

The decreases in drug seeking responses to intra-BLA D1 blockade, slow recovery to saline, and renewal in a novel context is similar to changes that occur during extinction, post-extinction reacquisition, and contextual renewal (Bouton, 1986; Bouton et al., 2012; Bouton and Todd, 2014). In our Experiment 3, however, these changes occurred in the presence of continued reinforcement of the response, meaning that the renewal that occurred with a change in context was not entirely dependent on nonreinforcement. Other studies have found that renewal occurs after counterconditioning (Peck and Bouton, 1990) and that renewal-like effects occur under other conditions in which the organism attends to the context to disambiguate conflicting information about the stimulus-outcome relation (Nelson and Callejas-Aguilera, 2007; Rosas and Aguilera-Callejas, 2007). Thus, contextual renewal can be applied to cases outside of the typical reinforcement followed by nonreinforcement situations and there is an emerging literature, suggesting that contexts can modulate specific response-outcome associations (Trask and Bouton, 2014).

\section{Possible mechanisms of D1 suppression on drug seeking and taking}

There are several mechanisms through which the suppressive effects of D1 antagonism could occur. A very general mechanism would be a disruption of activity in the amygdala that may operate through D1 or D2 receptor mechanisms. A number of studies have shown that a single administration of a D1 (Caine et al., 1995; AlleweireIdt et al., 2006) but not D2 antagonist (See et al., 2001) in the BLA has disrupted cocaine self-administration and administration of a D1 agonist in the BLA has been found to increase cocaine-seeking behavior (Mashhoon et al., 2009), consistent with the present results. Because cocaine self-administration increases DA release in the BLA and the nucleus accumbens (NAc; Hurd and Pontén, 2000 ) and D1 antagonism in the BLA has been found to block the excitability of DA on BLA projection neurons, it is possible that amygdalar blockade by $\mathrm{SCH} 23390$ may decrease the activity of D1 projection neurons and alter DA tone in the Nac to disrupt the primary reinforcing properties of cocaine. These types of mechanisms will clearly require further investigation.

The finding in Experiment 4 that D1 antagonism in the BLA induced a place aversion suggests that cues associated with $\mathrm{SCH} 23390$ may acquire aversive properties. This is consistent with other studies that have found that D1 antagonism blocks cocaine CPP (Nazarian et al., 2004) and can induce a conditioned place aversion when administered in the NAc (Shippenberg et al., 1991). These aversive properties may overshadow the rewarding properties of cocaine, causing self-administration to decrease independent of context, but when the antagonist is removed, the behavior recovers quickly. It also is possible that $\mathrm{SCH} 23390$ altered the rewarding value of cocaine itself, leading to a weakened reinforcer that failed to maintain responding. However, $\mathrm{SCH} 23390$ in the $\mathrm{CeA}$ did not induce a place aversion, although it resulted in an immediate disruption of responding for cocaine, suggesting a dissociation between the aversive effects of the compound itself and its effects on maintained responding for cocaine.

BLA neurons have been found to respond to both appetitive and aversive stimuli (Belova et al., 2007) and 
many studies have found that DA signaling in the amygdala is involved in aversive learning paradigms (Fadok et al., 2010; Darvas et al., 2011; Abraham et al., 2016a,b; Lee et al., 2017). A recent study found that population coding of stimulus and outcome neural ensembles in the BLA underwent learning-induced changes through the recruitment of unresponsive BLA neurons before learning (Zhang and Li, 2018), suggesting that subsets of BLA neurons may become engaged by one aspect of learning while other neurons become engaged by other aspects of the same learning process. Thus, it is possible that neurons within the BLA encode contextdependent (conditioned value) and context-independent (unconditioned value) features, which revealed themselves as stronger and weaker contextual renewal, respectively, in our experiments.

Given that dopamine has been shown to play a critical role in reinforcement processes, the decrease in drug seeking responses to intra-amygdalar D1 blockade suggests an interference of DA signaling that may represent outcome expectations. Many studies have shown that overexpectation of reward magnitude can lead to a decrease in appetitive conditioned responding (Lattal and Nakajima, 1998; Rescorla, 2007) and have implicated the $\mathrm{CeA}$ in Pavlovian overexpectation effects, with some evidence that the BLA may be involved with instrumental contingencies (Haney et al., 2010; Holland, 2016). Perhaps D1 antagonism in the amygdala alters the expected value of the reward and thereby creates a persistent overexpectation effect that weakens some aspect of the association between responding and cocaine.

In line with a role in Pavlovian-instrumental interactions, intra-BLA D1 blockade has been shown to block cueinduced instrumental responding (See et al., 2001). In Pavlovian-to-instrumental transfer tasks, BLA lesions result in deficits in specific cue-induced instrumental behavior, while CeA lesions show deficits in general nonspecific cue-induced instrumental behavior (Corbit and Balleine, 2005). These results have been interpreted to suggest the BLA to encode outcome value with specific sensory features, while the $\mathrm{CeA}$ to encode the general representation of motivational processes. Analogously, in devaluation tasks, BLA lesion animals decrease instrumental responding to both non devalued and devalued outcomes, suggesting a general devaluation across different cues to remain intact, while CeA lesions continued to show selective devaluation (Corbit and Balleine, 2005). In line with these results, intra-BLA D1 blockade may cause a devaluation of the reinforcer that continues to suppress responses across context shifts. In contrast, intra-CeA blockade might enable the BLA to show specific cue-induced instrumental behavior and increase responding on a contextual renewal test. These findings also are consistent with work from Thrailkill and Bouton (2015) showing that specific goal-directed responding can transfer across contexts (such as occurred with our BLA suppression), but stimulus-response learning is sensitive to context change (such as occurred with our CeA suppression). Clearly there are multiple accounts that warrant further study, but our findings suggest additional ways that the BLA and CeA may make distinct contributions to value representation, adding evidence for a parallel rather than serial model of amygdala function (Balleine and Killcross, 2006).

\section{A model of relapse under continued access conditions}

Many models of drug relapse incorporate abstinence and relapse under non-reinforced conditions to test how drug-associated cues can alter motivated behavior. While these results have been invaluable to understanding how drug associated cues can motivate instrumental responding, the therapeutic challenges with forced abstinence models are that social, environmental, and emotional events can robustly trigger a relapse of drug seeking and taking behavior. Alternate therapeutic approaches that decrease drug seeking responses under safe drug access conditions need to be explored involving pharmacological blockade and chemical aversion therapy (Dole et al., 1966; Frawley and Smith, 1990; Elkins et al., 2017). Recently, additional animal models of relapse under continued access conditions, such as punishment-based and conflict-based models have been used to mirror other human clinical abstinence and relapse behaviors (Marchant et al., 2013). In these continued access conditions, BLA inactivation has been found to have opposite effects on contextual renewal after punishment compared to extinction (Pelloux et al., 2018). Additionally, studies have found that amygdala neurons can serve alternate functions under different conditions. For example, the BLA and $\mathrm{CeA}$ are both engaged during contextual renewal (Knapska and Maren, 2009), but inactivation of the BLA and $\mathrm{CeA}$ can have different effects on acquisition, extinction, and expression of reward-related behaviors (Kruzich and See, 2001). Many studies have shown that the BLA and the CeA have distinct anatomic and functional circuits that modulate DA efflux in the NAc (Everitt et al., 1999; Phillips et al., 2003; Shiflett and Balleine, 2010). Given these results, more research into how the different subdivisions of the amygdala can alter the motivational and associative processes of reward may hold the key to therapeutic interventions that are successful and resistant to relapse.

\section{References}

Abraham AD, Neve KA, Lattal KM (2014) Dopamine and extinction: a convergence of theory with fear and reward circuitry. Neurobiol Learn Mem 108:65-77.

Abraham AD, Neve KA, Lattal KM (2016a) Effects of D1 receptor knockout on fear and reward learning. Neurobiol Learn Mem 133: 265-273.

Abraham AD, Neve KA, Lattal KM (2016b) Activation of D1/5 dopamine receptors: a common mechanism for enhancing extinction of fear and reward-seeking behaviors. Neuropsychopharmacology 41:2072

Alaghband Y, Kramár E, Kwapis JL, Kim ES, Hemstedt TJ, López AJ, White AO, Al-Kachak A, Aimiuwu OV, Bodinayake KK, Oparaugo NC, Han J, Lattal KM, Wood MA (2018) CREST in the nucleus accumbens core regulates cocaine conditioned place preference, cocaine-seeking behavior, and synaptic plasticity. J Neurosci 38: 9514-9526.

Alleweireldt AT, Weber SM, Kirschner KF, Bullock BL, Neisewander JL (2002) Blockade or stimulation of D1 dopamine receptors at- 
tenuates cue reinstatement of extinguished cocaine-seeking behavior in rats. Psychopharmacology (Berl) 159:284-293.

Alleweireldt AT, Hobbs RJ, Taylor AR, Neisewander JL (2006) Effects of SCH-23390 infused into the amygdala or adjacent cortex and basal ganglia on cocaine seeking and self-administration in rats. Neuropsychopharmacology 31:363-374.

Balleine BW, Killcross S (2006) Parallel incentive processing: an integrated view of amygdala function. Trends Neurosci 29:272279.

Baxter MG, Murray EA (2002) The amygdala and reward. Nat Rev Neurosci 3:563-573.

Belova MA, Paton JJ, Morrison SE, Salzman CD (2007) Expectation modulates neural responses to pleasant and aversive stimuli in primate amygdala. Neuron 55:970-984.

Bernardi RE, Ryabinin AE, Berger SP, Lattal KM (2009) Post-retrieval disruption of a cocaine conditioned place preference by systemic and intrabasolateral amygdala beta2- and alpha1-adrenergic antagonists. Learn Mem 16:777-789.

Bouton ME (1986) Slow reacquisition following the extinction of conditioned suppression. Learn Motiv 17:1-15.

Bouton ME, Todd TP (2014) A fundamental role for context in instrumental learning and extinction. Behav Process 104:91-98.

Bouton ME, Winterbauer NE, Todd TP (2012) Relapse processes after the extinction of instrumental learning: renewal, resurgence, and reacquisition. Behav Process 90:130-141.

Caine SB, Heinrichs SC, Koob GF (1995) Effects of the dopamine D-1 antagonist SCH 23390 microinjected into the accumbens, amygdala or striatum on cocaine self-administration in the rat. Brain Res 692:47-56.

Chen BT, Yau H-J, Hatch C, Kusumoto-Yoshida I, Cho SL, Hopf FW, Bonci A (2013) Rescuing cocaine-induced prefrontal cortex hypoactivity prevents compulsive cocaine seeking. Nature 496:359362.

Corbit LH, Balleine BW (2005) Double dissociation of basolateral and central amygdala lesions on the general and outcome-specific forms of Pavlovian-instrumental transfer. J Neurosci 25:962-970.

Crombag HS, Shaham Y (2002) Renewal of drug-seeking by contextual cues after prolonged extinction in rats. Behav Neurosci 116: 169-173.

Cunningham CL, Gremel CM, Groblewski PA (2006) Drug-induced conditioned place preference and aversion in mice. Nat Protoc 1:1662-1670.

Darvas M, Fadok JP, Palmiter RD (2011) Requirement of dopamine signaling in the amygdala and striatum for learning and maintenance of a conditioned avoidance response. Learn Mem 18:136143.

Dole VP, Nyswander M, Kreek MJ (1966) Narcotic blockade. Arch Internal Med 118:304-309.

Elkins RL, Richards TL, Nielsen R, Repass R, Stahlbrandt H, Hoffman HG (2017) The neurobiological mechanism of chemical aversion (emetic) therapy for alcohol use disorder: an fMRI study. Front Behav Neurosci 11:1-8.

Everitt BJ, Parkinson JA, Olmstead MC, Arroyo M, Robledo P, Robbins TW (1999) Associative processes in addiction and reward. The role of amygdala-ventral striatal subsystems. Ann NY Acad Sci 877:412-438.

Fadok JP, Darvas M, Dickerson TMK, Palmiter RD (2010) Long-term memory for pavlovian fear conditioning requires dopamine in the nucleus accumbens and basolateral amygdala. PLoS One 5:1-6.

Fotros A, Casey KF, Larcher K, Verhaeghe JA, Cox SM, Gravel P, Reader AJ, Dagher A, Benkelfat C, Leyton M (2013) Cocaine cue-induced dopamine release in amygdala and hippocampus: a high-resolution PET [18F]fallypride study in cocaine dependent participants. Neuropsychopharmacology 38:1780-1788.

Frawley PJ, Smith JW (1990) Chemical aversion therapy in the treatment of cocaine dependence as part of a multimodal treatment program: treatment outcome. J Subst Abuse Treat 7:21-29.

Gallagher M, Graham PW, Holland PC (1990) The amygdala central nucleus and appetitive Pavlovian conditioning: lesions impair one class of conditioned behavior. J Neurosci 10:1906-1911.
Guarraci FA, Frohardt RJ, Kapp BS (1999) Amygdaloid D1 dopamine receptor involvement in Pavlovian fear conditioning. Brain Res 827:28-40.

Guarraci FA, Frohardt RJ, Falls WA, Kapp BS (2000) The effects of intra-amygdaloid infusions of a D2 dopamine receptor antagonist on Pavlovian fear conditioning. Behav Neurosci 114:647-651.

Hamlin AS, Blatchford KE, McNally GP (2006) Renewal of an extinguished instrumental response: neural correlates and the role of D1 dopamine receptors. Neuroscience 143:25-38.

Hamlin AS, Newby J, McNally GP (2007) The neural correlates and ole of D1 dopamien receptors in renewal of extinguished alcoholseeking. Neuroscience 146:526-536.

Haney RZ, Calu DJ, Takahashi YK, Hughes BW, Schoenbaum G (2010) Inactivation of the central but not the basolateral nucleus of the amygdala disrupts learning in response to overexpectation of reward. J Neurosci 30:2911-2917.

Hietala J, Seppälä T, Lappalainen J, Syvälahti E (1992) Quantification of SCH 39166, a novel selective D1 dopamine receptor antagonist, in rat brain and blood. Psychopharmacology (Berl) 106:455-458.

Holland PC (2016) Effects of amygdala lesions on overexpectation phenomena in food cup approach and autoshaping procedures. Behav Neurosci 130:357-375.

Hurd YL, Pontén M (2000) Cocaine self-administration behavior can be reduced or potentiated by the addition of specific dopamine concentrations in the nucleus accumbens and amygdala using in vivo microdialysis. Behav Brain Res 116:177-186.

Hurd YL, McGregor A, Pontén M (1997) In vivo amygdala dopamine levels modulate cocaine self-administration behaviour in the rat: D1 dopamine receptor involvement. Eur J Neurosci 9:2541-2548. Janak PH, Tye KM (2015) From circuits to behaviour in the amygdala. Nature 517:284-292.

Johnson AW, Gallagher M, Holland PC (2009) The basolateral amygdala is critical to the expression of Pavlovian and instrumental outcome-specific reinforcer devaluation effects. J Neurosci 29:696-704.

Knapska E, Maren S (2009) Reciprocal patterns of c-Fos expression in the medial prefrontal cortex and amygdala after extinction and renewal of conditioned fear. Learn Mem 16:486-493.

Kruzich PJ, See RE (2001) Differential contributions of the basolateral and central amygdala in the acquisition and expression of conditioned relapse to cocaine-seeking behavior. J Neurosci 21:RC155.

Lattal KM, Nakajima S (1998) Overexpectation in appetitive Pavlovian and instrumental conditioning. Anim Learn Behav 26:351-360.

Lee JH, Lee S, Kim JH (2017) Amygdala circuits for fear memory: a key role for dopamine regulation. Neuroscientist 23:542-553.

Marchant NJ, Campbell EJ, Pelloux Y, Bossert JM, Shaham Y (2019) Context-induced relapse after extinction versus punishment: similarities and differences. Psychopharmacology (Berl) 236:439-448.

Marchant N, Li X, Shaham Y (2013) Recent developments in animal models of drug relapse. Cur Opin Neurobiol 23:675-683.

Mashhoon Y, Tsikitas LA, Kantak KM (2009) Dissociable effects of cocaine-seeking behavior following D1 receptor activation and blockade within the caudal and rostral basolateral amygdala in rats. Eur J Neurosci 29:1641-1653.

Meil WM, See RE (1997) Lesions of the basolateral amygdala abolish the ability of drug associated cues to reinstate responding during withdrawal from self-administered cocaine. Behav Brain Res 87: 139-148.

Nazarian A, Russo SJ, Festa ED, Kraish M, Quinones-Jenab V (2004) The role of D1 and D2 receptors in the cocaine conditioned place preference of male and female rats. Brain Res Bull 63:295-299.

Nelson JB, Callejas-Aguilera JE (2007) The role of interference produced by conflicting associations in contextual control. J Expl Psych: Anim Behav Process 33:314.

Parkinson JA, Robbins TW, Everitt BJ (2000) Dissociable roles of the central and basolateral amygdala in appetitive emotional learning. Eur J Neurosci 12:405-413.

Paxinos G, Watson C (1998) The rat brain in stereotaxic coordinates. Ed 4. San Diego: Academic Press. 
Peck CA, Bouton ME (1990) Context and performance in aversiveto-appetitive and appetitive-to-aversive transfer. Learn Motiv 21: 1-31.

Pelloux Y, Minier-Toribio A, Hoots JK, Bossert JM, Shaham Y (2018) Opposite effects of basolateral amygdala inactivation on contextinduced relapse to cocaine seeking after extinction versus punishment. J Neurosci 38:51-59.

Phillips AG, Ahn S, Howland JG (2003) Amygdalar control of the mesocorticolimbic dopamine system: parallel pathways to motivated behavior. Neurosci Biobehav Rev 27:543-554.

Pizzimenti CL, Navis TM, Lattal KM (2017) Persistent effects of acute stress on fear and drug-seeking in a novel model of the comorbidity between post-traumatic stress disorder and addiction. Learn Mem 24:422-431.

Rescorla RA (2007) Renewal after overexpectation. Anim Learn Behav 35:19-26.

Rosas JM, Aguilera-Callejas JE (2007) Acquisition of a conditioned taste aversion becomes context dependent when it is learned after extinction. Quart J Experi Psych 60:9-15.

See RE, Kruzich PJ, Grimm JW (2001) Dopamine, but not glutamate, receptor blockade in the basolateral amygdala attenuates conditioned reward in a rat model of relapse to cocaine-seeking behavior. Psychopharmacology (Berl) 154:301-310.
See RE, Fuchs RA, Ledford CC, Mclaughlin J (2003) Drug addiction, relapse, and the amygdala. Ann NY Acad Sci 985:294-307.

Shiflett MW, Balleine BW (2010) At the limbic-motor interface: disconnection of basolateral amygdala from nucleus accumbens core and shell reveals dissociable components of incentive motivation. Eur J Neurosci 32:1735-1743.

Shippenberg TS, Bals-Kubik R, Huber A, Herz A (1991) Neuroanatomical substrates mediating the aversive effects of $D-1$ dopamine receptor antagonists. Psychopharmacology (Berl) 103:209-214.

Thrailkill EA, Bouton ME (2015) Contextual control of instrumental actions and habits. J Exp Psychol Anim Learn Cogn 41:69-80.

Trask S, Bouton ME (2014) Contextual control of operant behavior: evidence for hierarchical associations in instrumental learning. Learn Behav 42:281-288.

Weiss F, Maldonado-Vlaar CS, Parsons LH, Kerr TM, Smith DL, Ben-Shahar O (2000) Control of cocaine-seeking behavior by drug-associated stimuli in rats: effects on recovery of extinguished operant-responding and extracellular dopamine levels in amygdala and nucleus accumbens. Proc Natl Acad Sci USA 97: $4321-4326$.

Zhang X, Li B (2018) Population coding of valence in the basolateral amygdala. Nature Commun 9:5195. 